\title{
Environment-person interactions enabling walking in later life
}

Charles Musselwhite

Centre for Innovative Ageing, Swansea University, Swansea, UK.

Dr Charles Musselwhite

Associate Professor/Reader in Gerontology

Centre for Innovative Ageing

College of Human and Health Sciences

Rm 309, Vivian Building

Swansea University

Singleton Park

Swansea

SA2 8PP.

c.b.a.musselwhite@swansea.ac.uk

01792518696 


\section{Environment-person interactions enabling walking in later life}

\section{Abstract}

Traditionally, theory suggests the ageing individual is strongly influenced by the environment and has difficulties in overcoming distance and space. Recently, however, theory has moved to suggest older people possess greater agency, being more capable of selecting and mastering their environments and spaces according to their needs and preferences. This paper suggests both opposing theories are correct for differing groups. Observations and surveys of older people $(n=365)$ in public space examined how far person-environment agency is present in active use of outdoor space, measured by confidence to use and explore space, in three locations (urban shopping centres, suburban residential area and an area of shared space). In all three areas dominance of the space was associated with being male and having higher levels of reported health, confidence and higher socio-economic status. Only $11 \%$ of participants walked at least as fast as the UK department for transport guidance on crossing speeds.

Keywords: pedestrian; environment; older people; health; confidence; gender 


\section{Introduction}

Maintaining mobility in later life is important for maintaining health and wellbeing, affording older people close contact with family and friends, enabling access to services, shops and facilities, to engage in sports and leisure and to enhance connectivity and inclusion while remaining actively engaged with society (WHO, 1999). Continuing active travel in later life also has additional direct physical health benefits, for example, regular walking or cycling can reduce cardiovascular disease by around 30\% and reduce all-cause mortality by 20\% (Hamer and Chider, 2008), through reducing the risk of coronary heart disease, stroke, cancer, obesity and type 2 diabetes (NICE, 2012). It also keeps the musculoskeletal system healthy and promotes mental wellbeing (NICE, 2012). In addition, travel is important for affective needs including the need for independence, freedom and status (Musselwhite and Haddad, 2010). A lack of personal mobility can be a significant contributing factor to societal exclusion (Preston and Raje, 2007) and restricted physical mobility associated with ageing in some people can reduce this mobility, especially when giving-up driving (Musselwhite and Shergold, 2013). Unsurprisingly, older people who are restricted in getting out and about are far more likely to report being lonely and depressed (Fonda, et al., 2001; Ling and Mannion, 1995) and have reduced quality of life (Schlag, et al., 1996).

Being a pedestrian in later life is a particular problem, in the UK, older people represent around $16 \%$ of the population, yet around $43 \%$ of all pedestrians killed (DfT, 2009). Countries that have more stringent licence renewal process for older drivers, can face an increase in the number of road traffic incidents with older people, as people switch from the car to being a pedestrian (Mitchell, 2008, 2011). Some of the increase is attributed to changes in physiology, for example a tightening of joints and muscles and an increase 
in likelihood of balance problems, resulting in slower movement and less ability to change gait or alter movement, coupled with poorer eyesight and a lack of confidence, especially in light of previous falls (see Dunbar et al., 2004 for review). Older people themselves report particular barriers with the pedestrian environment including lack of time to cross the road at formal crossings, cracked or uneven pavements or kerbs at formal and informal crossings, poor quality paths, lack of amenities (especially benches and toilets), and unattractive, unwelcoming and inapproachable spaces (see Alves et al., 2008; IDGO, 2013, Musselwhite, 2011).

Solutions to improve things for a pedestrian have either focussed heavily on changing the built environment to meet the needs and requirements of the older person or individual programmes to help older people gain confidence to use the space, including programmes to help them cross the road, improve their balance or providing travel information. Evaluation of such changes often show some short term improvement with use of space and confidence, even showing reduced risk (e.g. Gillespie et al. 2009). However, what might be best is to view how older people use the space themselves initially; are they passively influenced by the environment or are they more active and adapt and change? In addition, could both of these hold true and if so, what might determine whether some older people are more or less actively engaged with their environment? Traditionally, theory has seen the ageing individual as strongly influenced by the environment with difficulties in overcoming distance and space encapsulated in concepts such as 'environmental press', 'person-environment reactivity' (Lawton and Nahemow 1973), or environmental determinism (cf Hammond and Musselwhite, 2013) . Recently, however, theory has moved to suggest older people possess greater agency, being more capable of selecting and mastering their 
environments and spaces according to their needs and preferences (Lawton 1999; Wahl and Lang 2006). This paper aims to examine which theory is correct in an ageing cohort through observations and intercept surveys of older people $(n=365)$ in different public space measured by confidence to use and explore space, in three key public locations (urban shopping centres, suburban residential area and an area of shared space). In order to examine older people's use of space three analyses were carried out, an examination of pedestrian-pedestrian conflicts, measurement of walking speed and an assessment of pedestrian positioning. Conflict analysis and position of the pedestrian in relation to the carriageway is important to assess confidence with use of the space (e.g. Moody and Melia, in press) and walking speed is related to health and morbidity (Dumurgier et al., 2009; Guralnik et al. 2000, Guralnik \& Ferrucci, 2003) but can also be a barrier to getting out and about (IDGO 2013; Lord et al., 2010; Zijlstra, 2007). Each of thethree analyses are examined in relationship to background details including age, gender and socio-economic status and self-reported measures of health, confidence and experience.

\subsection{Methodology}

\subsection{Case Study locations}

Three locations were chosen to represent three different walking environments, an urban shopping area, a suburban residential areas and an area of shared space. They were all located in a similar region in the North West of England and Wales..Location one, the urban shopping area, was chosen in Shrewsbury, UK. Shrewsbury is an historic market town, with a population in the town itself of 71,715 (ONS, 2013). It has five wards surrounding the town in the bottom $30 \%$ of Lower Super Output Areas (Shropshire Council, 2014). The town centre location which was chosen was at the 
western edge of a pedestrianised area so that vehicles were in the carriageway and pedestrians were generally using the pavement. Vehicles were generally very slow (no measurements taken but not much faster than walking space due to volume of traffic). Location two was chosen 1.5 miles from the centre of a town to represent a suburban area. The area opposite the Peacock public house on a main arterial road leading out of the centre of Chester was chosen. The location has similar demographics to Shrewsbury with a population of 90,524 and similar deprivation statistics in the lower super output areas represented (ONS, 2013). The third location was chosen at the nearest shared space location, Castle Square, Caernarfon. Shared space was chosen because it represents a relatively new design technique involving the removal traditional road characteristics associated with the highway including kerbs, road markings, traffic signals, signs and barriers to encourage greater sense of sharing by vehicles and negotiation in interactions between pedestrians and vehicles (HamiltonBaillie, 2008; Hammond and Musselwhite, 2013). A much smaller population of 9,615 is found here (ONS, 2013), but the location is central to a number of places and is of historic value, so it was expected that the location would have a higher number of visitors and tourists than would be expected for a town of its size. The locations were selected around services and shops to maximise the number of potential users. In each location an area at an intersection was chosen where pedestrians would be travelling through from other locations and would interact with other types of movement, including vehicles and cyclists to examine walking behaviour where conflicts may occur. The urban shopping area contained a variety of chain stores, a cafe and coffee shop in the vicinity, the suburban location included a row of convenience shops and a health centre (primary care) and the shared space area included a variety of smaller chain stores and independent shops. All were located near to offices and the suburban 
case study area also included a small industrial estate nearby. All three areas were adjacent (or were part of, in the case of the shared space area) to roads with similar levels of fairly busy and mixed use traffic.

\subsection{Procedure and tools}

A camera was set up to observe walking behaviour on a weekday over the period of an hour, three times a day, between 8.30 and 9.30 to capture a time when the location may include commuters, $10.30-11.30$ to capture a time when people arrive at the space for shopping or leisure purposes, and 3.00-4.00 to capture a time when local schools may dominate the space. The films focussed in on a $10 \mathrm{~m}^{2}$ area and a $10 \times 10$ mesh grid was placed on the picture, so incidents and direction of travel could be plotted. The camera was positioned on a tripod to the edge of the road, such that people would not have to walk around it, it appeared relatively covertly but was not hidden. In each of the three locations the camera was set at the same angle and the same height. In all three locations the camera was positioned so there was a similar physical layout, even though the specific elements of design were different (see figure 1). In all cases the camera was located in very similar position, so that a $10 \mathrm{~m}^{2}$ area include road carriageway and unbroken length of pavement (sidewalk), with no noticeable cracks or significant unevenness, no changesin height and free from street furniture and clutter. All were of almost identical size (pavement was divided into two equal strips for analysis of pedestrian location between that of inside away from the road carriageway and near or next to the carriageway). In all three cases the area ended at a junction with a road. The shared space area included an element that used to have a pavement and used to be the carriageway, and although a kerb was no longer present it was still demarcated 
somewhat with different patterned surfacing. Permission was given by the local council to allow the analysis to take place and people were fully debriefed and consent taken in the intercept studies. All data, including film, was deleted after analysis had taken place. Observers watched the film on laptops next to the camera and were positioned in case of any queries from passers-by as to the nature of the filming; in practice no one asked any details. The films were observed by 2 individuals who in the first instance estimated the age of the pedestrians passing through the space. If the pedestrian was adjudged to be over 65 (as agreed by both researchers), then extra details were collected on the person, including examined speed of walking and a note on any conflicts. The walking speed of a particular pedestrian was computed by dividing the known length of the area under investigation by the travel time taken by that pedestrian, the camera's own software was able to do this and parallax errors minimised by standardising location and angle of sight. Conflict analysis, based on Hyden's (1987) definition, involved researchers recording details either when an individual deviated from their path (recorded as yielded) or caused another to deviate from their path (recorded as did not yield) because of a potential clash with another person, cyclist or vehicle. Both researchers had to agree that this had happened for it to be recorded, in total 27 incidents were agreed by the two researchers, a further 3 could not be agreed upon and were eliminated from the analysis, hence there was $90 \%$ inter-observer reliability. No pedestrian-vehicle or pedestrian- cyclist interactions were noted in this instance due to very low numbers observed, and hence analysis was kept to pedestrian-pedestrian conflicts. In addition, the dominant position of the person across the observation was noted and traced on the $10 \mathrm{~m}^{2}$ area and assigned one of four categories based on where she or he had walked - 1 kept inside furthest away from carriageway, 2 kept closer to the carriageway, 3 mixed between 1 and 2 and 4 on (former in the case of shared space) roadway space (see figure 
1) Observers noted any disagreements between themselves and if a situation could not be resolved then the participant and associated data was eliminated from the study. Finally, speed of walking was captured using software on the trace of the $10 \mathrm{~m}^{2}$ area in real time, when the distance as known and calculated in meters/second $(\mathrm{m} / \mathrm{s})$.

Insert figure 1 here

Participants aged over 65 were then intercepted at the edge of the observation area and a series of questions were asked by another researcher. Almost all older people identified that actually were over 65 , took part in the intercept survey $(n=365, N=407 ; 89.7 \%)$. Where individuals were with other people ( 2 or more) these was included as separate people. The intercept survey asked the following details, background data (age, gender), socio economic status (job or former job), self-reported health, self-reported confidence with use of the space, self-reported experience of using the space (how often they walk in the space). Socio-economic status was collected by top household earner's main income, in line with NRS (2008) and a social grade category from A to E is given. One exception occurred in that retired individuals were classified according to the top job they had held across their lifetime (rather than being placed in social grade $\mathrm{E}$ as 'pensioner' as NRS (2008) does). Table 1 shows the descriptions of each grade and the $\%$ of the UK population in each of them at 2008. Simple self-reported measures were used to minimise intrusion and time of the participant which helped improve the response rate. Standardised questions of health and wellbeing could have been used but would have taken extra time to complete. In any case, self-report in terms of health is known to have some validity (e.g. Reijneveld and Stronks, 2001) and experience of use and confidence as self-reported measure have been used in previous studies with some success (e.g. Hammond and Musselwhite, 2013). 
Insert table 1 here

\subsection{Participants}

A total of 365 people were observed, intercepted and surveyed. The average age of the 365 people was 70.52 years, with 184 being male and 181 being female. A total of $243(66.58 \%)$ were in groups of two or more (164 represented 82 pairs, 27 represented 9 groups of 3, 40 represented 10 groups of 4 and there was one group of 5 and 1 group of 7$)$ with 122 on their own $(33.42 \%)$. The distribution across the three sites was not quite even; as would be expected the urban shopping area had most people $(n=151)$, followed by the shared space $(n=117)$ and the suburban residential area had fewest ( $n=97)$. Most older people were observed and intercepted at 10.30-11.30 time frame $(n=176)$ and all areas followed a similar order with 3-4 having the next most people ( $\mathrm{n}=106)$, followed by $8.30-9.30$ in the morning having fewest $(\mathrm{n}=83)$ (see table 2). Males and females were distributed evenly across the locations and times, but more single people were found in the early slot and more groups in the middle time in the urban shopping location.

Insert table 2 here

\subsection{Data analysis}

Data from the observations were then assessed along with data from the questionnaire through the use of the Statistical Package for Social Sciences (SPSS). The program assisted with the statistical interpretation of data by examining significant differences in key areas. Descriptive data of the observations made, including pedestrian positioning, speed and conflict analysis, was detailed, followed by descriptive data collected from the intercept survey. Comparisons within the intercept data then took place, looking for correlations for example between self-report measures of health, 
confidence and experience and then examining how far these measures were related with gender and socio-economic status using t-tests to test for differences and with age assessing for correlations. Finally, tests were used to assess how far the different observations could be explained by the background data collected at the intercepts. To examine was there any differences between age and the self-report measures of health, confidence and experience and whether someone yielded or did not yield in the conflict analysis and their positioning of their walk, t-tests were used, and to assess against the speed of walking, correlations were carried out. To examine the categorical data of gender and socio-economic status and whether someone yielded or did not yield in the conflict analysis and their positioning of their walking, chi-squared tests were carried out and against the walking speed, t-test once again was used. Although low numbers were found in the conflict analysis, t-tests were still used despite equal variances not being assumed, non-parametric tests were found to yield similar results

\section{Results}

The findings are presented first from the observation in terms of location, speed and conflicts found when walking, followed by the data collected in the intercept surveys and then finally relationships between the observations and the intercept data.

\subsection{Location of walking}

The majority of participants walked in the area furthest away from the carriageway $(n=$ $235 ; 64.4 \%)$, followed by being closest to the carriageway $(n=96 ; 26.3 \%)$, mixed $(n=23$; $6.3 \%)$ and finally being in the carriageway $(n=11,3 \%)$. This varied across different locations (see table 3), with a higher percentage walking nearer the carriageway in the suburban residential area and a higher percentage of people both walking inside away from the carriageway and in the carriageway in the shared space area. A higher 
percentage of people walk between being inside away from and nearest the carriageway in the urban shopping area. A chi-squared test suggests these differences are significant, the type of location does significantly effect where an older pedestrian positions themselves $\left(\mathrm{x}^{2}(2, \mathrm{~N}=6)=38.37 ; \mathrm{p}<0.01\right)$.

Insert table 3 here

\subsection{Speed of walking}

Older people's average speed recorded at $0.95 \mathrm{~m} / \mathrm{s}$, the distribution is approaching normal with a skew of -0.1 and a kurtosis metric of -0.16 , although a Shaprio Wilks test shows this is significant at 0.05 but not significant at $0.01(0.99 ; \mathrm{df}=365 ; \mathrm{p}<0.05$; $\mathrm{p}>0.01$ ) and hence it is important to assume not quite normal distribution. (figure 2). The speeds significantly varied by location $(\mathrm{F}(362,2)=4.3 ; \mathrm{P}<0.05)$. Older people walked much quicker in urban shopping area $($ mean $=0.99 \mathrm{~m} / \mathrm{s} ; \mathrm{sd}=0.22)$ than they $\mathrm{did}$ in residential suburban $($ mean $=0.93 \mathrm{~m} / \mathrm{s} ; \mathrm{sd}=0.21)$ and shared space $($ mean $=0.91 \mathrm{~m} / \mathrm{s}$;

$\mathrm{sd}=0.21$ ); the difference between speeds observed in the urban shopping area and shared space being significant on Tukey's post-hoc test.

Insert figure 2 here

\subsection{Conflict analysis}

The 27 incidents of pedestrian-pedestrian conflict took place across all areas, with the most frequent occurring in urban shopping and shared space areas, with more yielding in urban than in shared space (see table 4), though differences across areas in terms of yielding are due to chance $\left(\mathrm{x}^{2}(2, \mathrm{~N}=27)=2.78 ; \mathrm{p}>0.05\right)$.

Insert table 4 here

\subsection{Background details of the participants}


The 365 people that were intercepted, had an average age of 70.52 years. Females were significantly older than males (female mean age $=71.2 ; \mathrm{sd}=5.42$ and male mean age $=69.84$ years; $\mathrm{sd}=5.48 ; \mathrm{t}(363)=2.38 ; \mathrm{p}<0.05)$. They reported good health $(1.84$ on average on a scale from $1=$ very good to $6=$ very poor), they were fairly experienced ( 2.48 on a scale of $1=$ very experienced (i.e. at least once a week use) to $6=$ very inexperienced (i.e. use equating to less than once a year)) and fairly confident ( 2.56 on a scale of $1=$ very confident to 6 very unconfident) with using the environment within which they were observed and intercepted (see table 5).

Socio-economic status was reported by asking what job the individual had held with $29.6 \%$ from $\mathrm{AB}$ groups, $48.5 \%$ from $\mathrm{C} 1 \mathrm{C} 2$ groupings and $21.9 \%$ from $\mathrm{DE}$ groupings. The figures from the respondents is fairly similar to the national statistics (see table 1 and NRS, 2008) with slightly more coming from $\mathrm{AB}$ and fewer from $\mathrm{DE}$, which is to be expected as highest ever job across lifecourse was noted and E contains less permanent states of unemployment and also that of being retired which for the purposes of this research was eliminated.

There was no significant difference between self-reported health and socio-economic status $(\mathrm{F}(362,2)=0.33 ; \mathrm{p}>0.05)$ as might have been expected in later life, though perhaps taking data from those who were out and about means less healthy people may not be in the sample, after all, the average self-reported health is high at $1.84(1=$ very healthy through to 6-very unhealthy). There was no significant difference between gender and health either $($ male mean $=1.8 ; \mathrm{sd}=0.89 ;$ female mean $=1.88 ; \mathrm{sd}=0.94 ; \mathrm{t}(363)=0.77$; $\mathrm{p}>0.05)$. 
There was a relationship between self-reported confidence and socio-economic status $(F(362,2)=6.18 ; \mathrm{p}<0.01)$. Post-hoc tests reveal, as might be expected, those from $A B$ are significantly more confident than those in $\mathrm{C} 1 \mathrm{C} 2$ group and significantly more confident than those in DE group, though there is no difference between $\mathrm{C} 1 \mathrm{C} 2$ and $\mathrm{DE}$ in terms of confidence. Those from $\mathrm{AB}$ group are also significantly older (mean=72.09 years, $\mathrm{sd}=7.25)$ than those from $\mathrm{C} 1 \mathrm{C} 2($ mean=69.97 years, $\mathrm{sd}=4.41)$ and $\mathrm{DE}$ groups $($ mean=69.6; $\mathrm{sd}=4.38)(\mathrm{F} 362,2)=6.67 ; \mathrm{p}<0.01)$, though no significant difference between $\mathrm{C} 1 \mathrm{C} 2$ and DE groups with regards to age were found.

People were more familiar with the suburban location, than the shared space and urban shopping area, as might be expected as they shared space and urban area have wider pull for the types of shops and services they offer, however, the difference was not significant $(\mathrm{F}(2,362)=0.94 ; \mathrm{p}>0.05)$. There were differences, however, between experience of a using a space and gender, males would report higher experience with the area they were using (mean=2.34; $\mathrm{sd}=1.16)$ than females (mean=2.62; $\mathrm{sd}=1.37$ ) $(\mathrm{t}(363)=2.08 ; \mathrm{p}<0.05)$

People were also more confident of using the residential area than they were the urban shopping or shared space locations $(\mathrm{F}(2,362)=5.74 ; \mathrm{p}<0.01$; Tukey's post-hoc test suggests significant differences between confidence in residential areas and urban shopping and confidence in residential areas and shared space areas (both $\mathrm{p}<0.05)$. Hence, older people are significantly more confident in the residential area than they are in urban and shared space zones, despite having similar experience with using all three. There are no significant differences between gender and confidence (male mean=2.5; $\mathrm{sd}=1.32$; female mean=2.62; $\mathrm{sd}=1.37)$ with using the space $(\mathrm{t}(362)=0.88 ; \mathrm{p}>0.05)$ 
There is a significant correlation between self-reported confidence and self-reported health $(\mathrm{r}(365)=0.14 ; \mathrm{p}<0.01)$ and between self-reported confidence and self-reported experience $(\mathrm{r}(365)=0.12 ; \mathrm{p}<0.05)$, but no relationship between self-reported health and self-reported experience $(\mathrm{r}(365)=0.02 ; \mathrm{p}>0.05)$.

Insert table 5

\subsection{Relationship between background and conflict analysis}

Socio-economic status is related to yielding to other pedestrians in conflict situations, those from $\mathrm{AB}$ socio-economic groups are far more likely than those from $\mathrm{C} 1 \mathrm{C} 2$ and DE groups to be the non-yielding partner in conflicts (see table 6), a chi-squared test shows this is a significant difference $\left(\mathrm{x}^{2}(2, \mathrm{~N}=27)=17.243 ; \mathrm{p}<0.01\right)$. More females yield than do not yield to other pedestrians (table 6$)$ but this is not significant $\left(\mathrm{x}^{2}(1\right.$, $\mathrm{N}=27)=0.898 ; \mathrm{p}>0.05)$. In addition, confidence is also related, with those more confident significantly more likely not to yield to other pedestrians than those who are less confident $(\mathrm{t}(23)=2.92 ; \mathrm{p}<0.01$; table 7$)$. Health and experience (table 7) are not significantly related to yielding in conflict situations. Insert table 6 Insert table 7

\subsection{Relationship between background and walking speeds}

The difference between male and female walking speed was significant with older males $($ mean $=1 \mathrm{~m} / \mathrm{s} ; \mathrm{sd}=0.21)$ walking significantly faster than older females $($ mean $=0.89 \mathrm{~m} / \mathrm{s} ; \mathrm{sd}=0.21)(\mathrm{t}(363)=5.33 ; \mathrm{p}<0.01)$. Those from higher socio-economic background walk fastest on average (mean $=1 ; \mathrm{sd}=0.21)$ followed by those from middle 
socio-economic backgrounds (mean=0.94; $\mathrm{sd}=0.22$ ) and those from lower socioeconomic backgrounds walk slowest (mean $=0.9 ; \mathrm{sd}=0.2$ ). This is a significant difference $(F(362,2)=5.38 ; \mathrm{p}<0.01)$ and post-hoc tests show the difference is between $\mathrm{AB}$ group and $\mathrm{C} 1 \mathrm{C} 2$ group and between $\mathrm{AB}$ group and DE groups. Speed of walking is correlated to self-reported health $(\mathrm{r}(365)=0.28 ; \mathrm{p}<0.01)$ and confidence $(\mathrm{r}(365)=-0.18$; $\mathrm{p}<0.01)$, though not to experience of using the area $(\mathrm{r}(365)=-0.47 ; \mathrm{p}>0.05)$. There was no significant relationship between walking speed and whether individuals yielded or not in conflict with other pedestrians $(t(23)=0.43 ; \mathrm{p}>0.05)$.

\subsection{Relationship between background and pedestrian positioning}

There are significant gender differences between the spaces inhabited by older pedestrians. Males are significantly more likely to walk nearer the carriageway, vary their walk between inside and near the carriageway and walk in the carriageway (in shared space areas), females are more likely to walk furthest away from the carriageway $\left(x^{2}(2, N=3)=25.62 ; p<0.01 ;\right.$ table 8$)$.

Insert table 8

The higher the socio-economic group the more likely older pedestrians are to walk closer to the carriageway and whereas the lower-socio-economic groups are more likely to walk on the inside. However, these differences are not significant $\left(x^{2}(2, N=6)=4.65\right.$; $\mathrm{p}>0.05)$. In addition, the older the individual the more likely they are to walk inside, further away from the carriageway. However, differences are not significant $(\mathrm{F}(3,361)=0.34 ; \mathrm{p}>0.05)$

There are no significant differences between self-reported experience and pedestrian positioning $(\mathrm{F}(2,361)=0.68 ; \mathrm{p}>0.05)$ and no significant differences between self- 
reported confidence and pedestrian positioning $\mathrm{F}(2,361)=1.92 ; \mathrm{p}>0.05)$. There are significant differences between pedestrian positioning and self-reported health however $(F(3,361)=4.78 ; \mathrm{p}<0.01)$. Post-hoc tests reveal these are between nearest and furthest from the carriageway and between nearest and mixed positions, where those who walk nearest the carriageway continually are in significantly better health than those who walk further away from traffic or mix between being further away and being near the traffic.

Walking speed is significantly related to pedestrian positioning $(\mathrm{F}(3,361)=5.35 ; \mathrm{p}<0.01$; see table 12). Those that walk quickest are walking in the carriageway (mean=1.1 $\mathrm{m} / \mathrm{s}$ ), followed by those nearest the carriageway $(1 \mathrm{~m} / \mathrm{s})$, then those mixed between nearest and inside $(0.98 \mathrm{~m} / \mathrm{s})$, and finally those that walk slowest are those positioning themselves furthest away from the carriageway $(0.92 \mathrm{~m} / \mathrm{s})$. Post-hoc tests reveal the significant differences lie between the speeds of those inside away from the carriageway and those nearest the carriageway and those inside away from the carriageway and those in the carriageway.

\section{Discussion}

Key findings are highlighted in table 9, as can be seen the main differences surround gender and socio-economic status, health and confidence, this discussion picks up these themes. For the majority of the time older people are walking in a location as far away from the carriageway as possible. How far this is related to themselves shielding (psychologically and physically) away from traffic is unknown; it could simply be that people like to be near as possible to the buildings they may wish to use for shopping and services etc. Further research could examine the motivations for why people walk where they do, especially in relation to the intrusion of motor vehicles and in relation to 
different widths of pavements. Previous research on shared space has suggested that older people tend to stay within the location that used to be the old pavement and do not use the carriageway to walk in when shared space is found (Hammond and Musselwhite, 2013; Melia and Moody, in press). This research suggests this is not so surprising since people have got used to the norm of being away from the carriageway when walking across all three locations, though this does seem to be more emphasised in shared space. People do use the carriageway to walk in shared space areas, but this is rare and is almost exclusively done by males, something that concurs with the previous research in shared space (Moody, 2011 and Kaparias, 2010) suggesting the benefits of shared space may be more apparent to males than females (Melia and Moody, in press). Males are also more likely than females to inhabit space nearer the carriageway in all three locations, though why this should be is not clear, but authors have suggested urban areas can be seen as masculine spaces, perhaps bringing out the mastery and dominance of males to utilise all of the space, while the women assume defensive positions nearer buildings (e.g. Ahrentzen, 2003; Gherardi,1995, Weisman, 1994). Socio-economic status appears to be linked to space, those with higher socio-economic status are more likely to utilise space near or in the carriageway, though tests reveal this is not statistically significant. Self-reported health is a determinant of position of walking, with those reporting better health more likely to walk near or in the carriageway than those with lower self-reported health. These differences are intriguing but reasons are not really known, especially when familiarity or confidence is not related, nor is it known as to how far it qualitatively affects enjoyment and use of the space; more research in this area would be useful.

Insert table 9 
People walk much slower than the Department for Transport in the UK recommends. They suggest that local authorities implement crossings assuming a walking speed of $1.2 \mathrm{~m} / \mathrm{s}$. The findings here suggest that only $11 \%$ of older people were walking at $1.2 \mathrm{~m} / \mathrm{s}$ or above and although they were not crossing the road, it was an example of walking in a natural environment. Females are even further excluded, with fewer than $6 \%$ meeting this figure. This is similar to previous research (Asher et al., 2012, Newton and Ormerod, 2007) and fear of not being quick enough to cross the road is known to restrict people leaving the home or limit their accessibility when out and about (IDGO 2013; Lord et al., 2010; Zijlstra, 2007). In addition, those from higher socio-economic backgrounds walk faster. Further research is needed as to why this might be as they are not in any better health in this study or have any additional experience with using the space. However, those who are in better health and those who self-report high confidence, regardless of their socio-economic background, also walk faster. However, walking slower may be a sign that individuals are enjoying their location and there are clear differences between average speeds and location with shared space location having the slowest mean speeds, perhaps because it is a more engaging and attractive environment (Hammond and Musselwhite, 2013). Speeds might be due to perceived safety of the location and volume of pedestrians in the area and density of walking, as well as reasons for being there in the first place. It is suggested future studies examine these elements in line with analysis of speed of walking.

There is relative balance between yielding and not yielding to other pedestrians in the conflict analysis. Due to low numbers of conflicts observed, the findings are not as robust as otherwise might be and it would be prudent to collect further data on conflicts and to look between different types of conflict examined. Further data could be collected examining more the relationship between different types of conflict; are there, 
for example, particular contexts or groups of people that older people are more or less likely to yield to. Again, having to move quickly for other people can be a source of anxiety that restricts older people using the public realm (IDGO, 2013; Musselwhite, 2011). The results here suggest that older people are not overrepresented in yielding and are almost as likely to dominate the space in conflict encounters, but of course is biased towards users of the space over non-users, and also involves yielding to other older people as well as people from other ages. Tentative findings suggest older people are less likely to yield in shared space, perhaps because others have more room to move for the older person, though obviously more data is needed on this as the number of conflict situations is low. Older people who are more confident and those from higher socioeconomic background are less likely to yield to other pedestrians, suggesting they are more likely to dominate the space than those form lower socio-economic groups and those with lower confidence. More detail is needed as to why this may be, it could be surmised, for example, that being confident may also allow appropriate yielding and a more equal pattern would be found. No relationship to health is also interesting, as having to yield or not may be related to physical ability or capacity to alter or change path for a pedestrian which those in poorer health would find more troublesome, for example not being able to change direction or to twist body to squeeze past another (Bock \& Beurskens 2010, Ko et al. 2010). Perhaps again those for who have less ability to change direction due to physiological difficulties again may not be represented here, having already been excluded from going out and using the space.

A limitation of the work is of course the self-reported measures of confidence, health and experience of using the area. These were, however, deliberately kept as simple as possible, to one question for each, to facilitate as many people as possible responding and not to take up their time. A balance was struck with this and a more robust measure 
and it must be remembered that how these were answered by different people may result in low reliability or validity. A further limitation is that the areas may well be fairly unique. Would similar findings be found in other locations, for example? An attempt was made to compare between locations within the study but as far as generalisation might be made, the descriptions of the case study allows readers to be able to judge this.

Taking the three different analyses of use of space by older people (conflict with other pedestrians, walking speeds and pedestrian positioning) it can be seen that there are some patterns that emerge. Self-reported experience, in terms of how often they have used the space, with a location has no significant relationship with use of space. This is probably because norms developed through habitual use of a space can encompass a variety of walking speeds, pedestrian positions and what to do in conflict situations. Those with higher confidence walk faster and yield less often in conflicts. This is related in a similar way to those from higher socio-economic status backgrounds who are more confident and also walk faster, yield less often and walk more quickly and are more likely than those less confident and from lower socio-economic backgrounds to walk closely to the carriageway. Health is related to faster walking speeds and walking more closely to the carriageway, but not to whether someone yields or not. Males are more likely to walk faster, walk in the carriageway or close to it in their pedestrian positioning and tend to yield slightly less often compared to females. Hence use of space is related to background characteristics of individuals. That said the type of location also affects individuals; older people are less likely to yield in shared space, walk faster in urban areas, slower in shared space areas and walk closer to the carriageway in suburban areas and in the carriageway in shared space areas. Hence, it can be concluded that opposing theories of environmental press or determinism 
(Lawton and Nahemov, 1973) and environmental agency (Lawton, 1999; Wahl and Lang, 2006) can both be present for different groups of people. The environment can dominate for some individuals resulting in more yielding, walking slower and walking away from the carriageway (females, from lower socio-economic backgrounds, reporting lower confidence and poorer health) and for others (males, from higher socioeconomic backgrounds, who report higher confidence and better health) they dominate the scene, not yielding, walking faster and walking closer or in the carriageway. More research is needed examining the interaction of these effects, perhaps with a wider sample. In addition, adding an element of desired speed, yielding and positioning may overcome assumptions made that yielding, walking slower and walking away from the carriageway is somewhat of an undesired situation. Analyses could be expanded by adding an activity index to examine dwelling and sitting behaviour too to help add a layer of quality of the public realm to the data. Increasing the analysis of conflicts to include a higher number of pedestrian conflicts, to improve the robustness of the analysis, and to examine conflicts with vehicles and cyclists would also be beneficial, including more analysis of carriageway crossing. Finally, motivations for use of the space could be added to examine if this effects how differently people use the space.

\section{Conclusions}

Older people use public space in different ways and these can be seen to be related in part to background details. The public realm needs to be designed to take account of these differences. Most pressingly this paper adds to the building consensus that $1.2 \mathrm{~m} / \mathrm{s}$ crossing time for older people probably does not reflect their normal walking speeds and that the UK Department for Transport recommendations need urgently updating.

In addition, quite why those from higher socio-economic backgrounds should be more dominant in their use of space is not known, perhaps it is related to norms developed in 
different types of job early on in life or to do with behaviours related to norms for that group, relating to time, prestige, privilege and social position. Whatever the reason it remains that designers of public space need to think how to encourage more confident use of space from those less dominant positions in society including those from lower socio-economic backgrounds. In addition, older male pedestrians are more dominant in their use of the street space and again design needs to reflect more on the needs of older females. This could be that males feel more comfortable dominating urban and suburban space, perhaps because design has traditionally been unwittingly or deliberately masculine which may psychologically exclude female interaction (e.g. Ahrentzen, 2003; Gherardi,1995, Weisman, 1994). Designers also need to be aware of the potential exclusion of people by socio-economic background and encourage spaces that encourage use by all.

What the paper does not have here is those who are already isolated from the public realm, but maybe it points towards some barriers and enablers that could be focussed on to encourage greater use of public realm by older people. These include the need to accommodate different walking speeds and also to examine the need to encourage older people to use different parts of the pavement and carriageway. Shared space is one way of making this happen, but it both increases the number of people using the space nearest buildings and those using the carriageway. Lessons could be taken from the residential location, which included wider pavements and open fronts to shops and houses, which seem to facilitate older people to use a wider variety of space. Overall, the different needs of groups of older people must be examined further and taken into account in the design of streets. There are indications that some individuals feels the environment dominates them and for others they master and dominate the environment, 
the implications of which relating to perception of control and as barriers and enablers to using the outdoor environment warrant further examination.

\section{References}

Ahrentzen, S. 2003. The Space between the Studs: Feminism and Architecture. Signs: Journal of Women in Culture and Society, 29 (1), 179-206.

Alves, S., Aspinall, P., Ward Thompson, C., Sugiyama, T., Brice, R. and Vickers, A. 2008. Preferences of Older People for Environmental Attributes of Local Parks: The Use of Choice-Based Conjoint Analysis. Facilities 26 (11/ 12), 433-453.

Asher, L., Aresu, M., Falaschetti, E.A., and Mindell, J. 2012. Most older pedestrians are unable to cross the road in time: a cross-sectional study. Age and Ageing, 41, 690694.

Bock, O. \& Beurskens, R. 2010. Changes of locomotion in old age depend on task setting. Gait \& Posture 32 (4), 645-649.

DfT (Department for Transport) 2009. Road Casulaties Great Britain 2008. London: Department for Transport

Dumurgier J, Elbaz A, Ducimetière P, Tavernier B, Alpérovitch A, Tzourio C.2009. Slow walking speed and cardiovascular death in well functioning older adults: prospective cohort study, British Medical Journal, Nov 10, 229:b4460

Dunbar, G., Holland, C.A. and Maylor, E.A. 2004. Older Pedestrians: A Critical Review of the Literature Road Safety Research Report No. 37, Department for Transport, UK. London. Available at http://webarchive.nationalarchives.gov.uk/+/http:/www.dft.gov.uk/pgr/roadsafety/

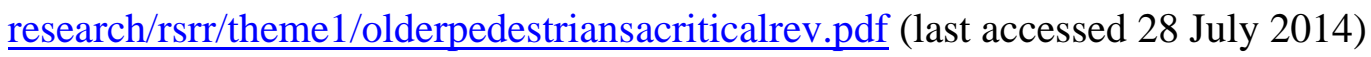


Fonda, S. J., Wallace, R. B., \& Herzog, A. R. 2001. Changes in driving patterns and worsening depressive symptoms among older adults. Journal of Gerontology: Social Sciences, 56B(6), S343- S351

Gherardi, S. (1995). Gender, symbolism and organizational cultures. Sage Publications: London

Gillespie LD, Robertson MC, Gillespie WJ, Lamb SE, Gates S, Cumming RG, Rowe BH. 2009. Interventions for preventing falls in older people living in the community. Cochrane Database of Systematic Reviews 2009, Issue 2. Art.No.: CD007146. DOI: 10.1002/14651858.CD007146.pub2.

Guralnik, J. M. \& Ferrucci, L. 2003. Assessing the building blocks of function: utilizing measures of functional limitation. American Journal of Preventive Medicine 25 (3 Suppl 2), 112-121.

Guralnik, J. M., Ferrucci, L., Pieper, C. F., Leveille, S. G., Markides, K. S., Ostir, G. V., Studenski, S., Berkman, L. F. \& Wallace, R. B. 2000. Lower extremity function and subsequent disability: consistency across studies, predictive models, and value of gait speed alone compared with the short physical performance battery. The Journals of Gerontology. Series A, Biological Sciences and Medical Sciences 55 (4), M221-31.

Hamer. M. and Chida, Y. 2008 Walking and primary prevention: a meta-analysis of prospective cohort studies; Br J Sports Med; 42(4):238-43

Hamilton-Baillie, B. 2008. "Towards Shared Space.” Urban Design International 13: $130-8$

Hammond, V. and Musselwhite, C B A 2013. The attitudes, perceptions and concerns of pedestrians and vulnerable road users to shared space: a case study from the UK. Journal of Urban Design 18(1), 78-97\# 
Hyden, C. 1987. The Development of Method for Traffic Safety Evaluation: The Swedish Traffic Conflict Technique. Bulletin 70. Lund Institute of Technology, Lund, Sweden,.

IDGO (2013) Inclusive Design for Going Outdoors Website accessed via http://www.idgo.ac.uk/ (last accessed $9^{\text {th }}$ December 2013).

Kaparias, I. Bell, M.G.H. Miri, A. Cheng, S. Greensted, J. Taylor, C 2010 Modelling the Willingness of Pedestrians to Share Space with Vehicles. UTSG Conference, Imperial College London. pp1-12

Ko, S. U., Hausdorff, J. M. \& Ferrucci, L. 2010. Age-associated differences in the gait pattern changes of older adults during fast-speed and fatigue conditions: results from the Baltimore longitudinal study of ageing. Age and Ageing 39 (6), 688-694.

Lawton, M. P. \& Nahemow, L. 1973. Ecology and aging process. In C. Eisdorfer \& M. P. Lawton (Eds.) The psychology of adult development and aging. Washington DC: American Psychological Association, 619-674.

Lawton, M.P. 1999. Environmental taxonomu: Generalizations from research with older adults. In S. Friedman \& T.Wachs (eds.) Measuring environment across the lifespan pp 91-124. Washington, DC: American Psychological Assocation

Ling, D. J. \& Mannion, R. 1995, Enhanced Mobility and Quality of Life of Older People: Assessment of Economic and Social Benefits of Dial-a- Ride Services, in Proceedings of the Seventh International Conference on Transport and Mobility for Older and Disabled People, Vol. 1,DETR, United Kingdom.

Lord, S. E., Weatherall, M. \& Rochester, L. 2010. Community ambulation in older adults: which internal characteristics are important? Archives of Physical Medicine and Rehabilitation 91 (3), 378-383. 
Mitchell, C. G. B. 2008. The Licensing of Older Drivers in Europe - A Case Study. Traffic Injury Prevention, 9: 360-366.

Mitchell, C. G. B. 2011. The Licensing and Safety of Older Drivers in Britain. Paper presented at the Transportation Research Board Conference, 30 Aug, Washington DC.

Moody, S. 2011. How do pedestrians move in a Shared Space scheme with high traffic flows? Is the pedestrian empowered or does a perception of risk give rise to anxiety and a disincentive to share the street with vehicles?.MSc Transport Panning dissertation.

Moody, S. and Melia, S. in press Shared space: Research, policy and problems. Proceedings of the Institution of Civil Engineers - Transport. ISSN 0965-092X

Musselwhite, C. 2011 Successfully giving up driving for older people. Discussion Paper. International Longevity Centre - UK.

Musselwhite, C. and Haddad, H. 2010. Mobility, accessibility and quality of later life. Quality in Ageing and Older Adults. 11(1), 25-37.

Musselwhite, C.B.A. and Shergold, I. 2013. Examining the process of driving cessation in later life. European Journal of Ageing. 10(2), 89-100

Newton, R. and Ormerod, M. 2007 The Design of Streets with Older People in Mind. IDGO Design Guide available at http://www.idgo.ac.uk/design_guidance/factsheets/Pedestrian_Crossings.htm (last accessed 28 July 2014).

NICE 2013. Walking and cycling: local measures to promote walking and cycling as forms of travel or recreation NICE public health guidance 41 available at http://www.nice.org.uk/nicemedia/live/13975/61629/61629.pdf (last accessed 22/11/13)

NRS (National Readership Survey) 2008 accessed via http://www.nrs.co.uk/lifestyle.html 
ONS (Office of National Statistics) (2013) Population statistics and estimates by area. Titchfield, Fareham: Office of National Statistics

Preston J.M., Raje F, 2007. Accessibility, Mobility and Transport-related Social Exclusion. Journal of Transport Geography, 15(3), 151-160

Reijneveld SA, and Stronks K 2001. The validity of self-reported use of health care across socioeconomic strata: a comparison of survey and registration data. Int $J$ Epidemiol 30:1407-1414

Schlag, B; Schwenkhagen, U \& Trankle, U. 1996. Transportation for the Elderly: Towards a User- Friendly Combination of Private and Public Transport, IATSS Research, 20(1).

Shropshire Council (2014). The Index of Multiple Deprivation 2010 in Shropshire County. Available online at https://shropshire.gov.uk/media/531151/IMD_Report_2010.pdf (last accessed 28 July 2014).

Wahl H.-W., Lang F. 2006 Psychological aging. A contextual view. In: Conn PM, editor. Handbook of models for human aging. Amsterdam: Elsevier; p. 881-895

Weisman, L 1994. Discrimination by Design: A Feminist Critique of the Man-Made Environment University of Illinois Press, $167-87$.

WHO (World Health Organisation) 1999 Charter on Transport, Environment and Health Zijlstra, G. A., van Haastregt, J. C., van Eijk, J. T., van Rossum, E., Stalenhoef, P. A. \& Kempen, G. I. 2007. Prevalence and correlates of fear of falling, and associated avoidance of activity in the general population of community living older people. Age and Ageing 36 (3), 304-309. 


\begin{tabular}{|l|l|l|}
\hline Social Grade & Description & $\%$ population \\
\hline A & High managerial, administrative or professional & 4 \\
\hline B & Intermediate managerial, administrative or professional & 23 \\
\hline C1 & $\begin{array}{l}\text { Supervisory, clerical and junior managerial } \\
\text { administrative or professional }\end{array}$ & 29 \\
\hline C2 & Skilled manual workers & 21 \\
\hline D & Semi and unskilled workers & 15 \\
\hline E & Casual or lowest grade workers, unemployed. & 8 \\
\hline
\end{tabular}

Table 1: Social grade of UK pop. by occupation of main household earner, after NRS (2008)

\begin{tabular}{|l|l|l|l|l|}
\hline & 8.30 and 9.30 & $10.30-11.30$ & $3.00-4.00$ & Total \\
\hline Urban shopping & $35(23.18 \%)$ & $69(45.7 \%)$ & $47(31.12 \%)$ & $151(41.37 \%)$ \\
\hline $\begin{array}{l}\text { Suburban } \\
\text { residential }\end{array}$ & $23(23.71 \%)$ & $45(46.39 \%)$ & $29(29.9 \%)$ & $97(26.58 \%)$ \\
\hline Shared space & $25(21.37 \%)$ & $62(52.99 \%)$ & $30(25.64 \%)$ & $117(32.05 \%)$ \\
\hline Total & $83(22.74 \%)$ & $176(48.22 \%)$ & $106(29.04 \%)$ & $365(100 \%)$ \\
\hline
\end{tabular}

Table 2: Number of participants at the three observation locations, at the three different times that observations took place.

\begin{tabular}{|l|l|l|l|l|}
\hline & $\begin{array}{l}\text { Inside away from } \\
\text { carriageway }\end{array}$ & $\begin{array}{l}\text { Nearest } \\
\text { carriageway }\end{array}$ & mixed & $\begin{array}{l}\text { In the } \\
\text { carriageway }\end{array}$ \\
\hline $\begin{array}{l}\text { Urban shopping } \\
(\mathrm{n}=151)\end{array}$ & $93(61.6 \%)$ & $43(28.5 \%)$ & $15(9.9 \%)$ & $0(0 \%)$ \\
\hline $\begin{array}{l}\text { Suburban } \\
\text { residential } \\
(\mathrm{n}=97)\end{array}$ & $58(59.8 \%)$ & $34(35.1 \%)$ & $5(5.2 \%)$ & $0(0 \%)$ \\
\hline $\begin{array}{l}\text { Shared space } \\
(\mathrm{n}=117)\end{array}$ & $84(71.8 \%)$ & $19(16.2 \%)$ & $3(2.6 \%)$ & $11(9.4 \%)$ \\
\hline $\begin{array}{l}\text { Total } \\
(\mathrm{n}=365)\end{array}$ & $235(64.4 / \%)$ & $96(26.3 \%)$ & $23(6.3 \%)$ & $11(3 \%)$ \\
\hline
\end{tabular}

Table 3: Pedestrian positioning by location type 


\begin{tabular}{|c|c|c|c|}
\hline & \multicolumn{2}{|c|}{ conflict with pedestrians } & \multirow{2}{*}{ Total } \\
\cline { 2 - 3 } & yield & did not yield & \\
\hline Urban shopping & 9 & 4 & 13 \\
Location Suburban residential & 2 & 1 & 3 \\
Shared space & 4 & 7 & 11 \\
Total & 15 & 12 & 27 \\
\hline
\end{tabular}

Table 4: Number of older people yielding to other pedestrians by location type.

\begin{tabular}{|l|l|l|l|l|l|l|}
\hline & $\begin{array}{l}\text { Av. } \\
\text { Age }\end{array}$ & $\begin{array}{l}\text { Socio- } \\
\text { economic } \\
\text { status }\end{array}$ & Gender & $\begin{array}{l}\text { Self- } \\
\text { reported } \\
\text { health }\end{array}$ & $\begin{array}{l}\text { Self- } \\
\text { reported } \\
\text { experience }\end{array}$ & $\begin{array}{l}\text { Self- } \\
\text { reported } \\
\text { confidence }\end{array}$ \\
\hline $\begin{array}{l}\text { Urban } \\
\text { shopping } \\
(\mathrm{n}=151)\end{array}$ & $\begin{array}{l}70.5 \\
(5.57)\end{array}$ & $\begin{array}{l}\mathrm{AB}=37.1 \% \\
\mathrm{C} 1 \mathrm{C} 2=37.1 \\
\% \\
\mathrm{DE}=25.2 \%\end{array}$ & $\begin{array}{l}\text { Male=77 } \\
\text { Female=74 }\end{array}$ & $\begin{array}{l}1.83 \\
(0.88)\end{array}$ & $2.58(1.33)$ & $2.74(1.25)$ \\
\hline $\begin{array}{l}\text { Suburban } \\
\text { residential } \\
(\mathrm{n}=97)\end{array}$ & $\begin{array}{l}70.65 \\
(5.32)\end{array}$ & $\begin{array}{l}\mathrm{AB}=25.8 \% \\
\mathrm{C} 1 \mathrm{C} 2=46.4 \\
\%\end{array}$ & $\begin{array}{l}\text { Male=46 } \\
\text { Female=51 } \\
\mathrm{DE}=27.8 \%\end{array}$ & $\begin{array}{l}1.68 \\
(0.92)\end{array}$ & $2.35(1.25)$ & $2.18(1.19)$ \\
\hline $\begin{array}{l}\text { Shared } \\
\text { space } \\
(\mathrm{n}=117)\end{array}$ & $\begin{array}{l}70.43 \\
(5.55)\end{array}$ & $\begin{array}{l}\mathrm{AB}=22.2 \% \\
\mathrm{C} 1 \mathrm{C} 2=65 \% \\
\mathrm{DE}=12.8 \%\end{array}$ & $\begin{array}{l}\text { Male=61 } \\
\text { Female=56 }\end{array}$ & $\begin{array}{l}1.98 \\
(0.95)\end{array}$ & $2.46(1.23)$ & $2.65(1.52)$ \\
\hline Total & $\begin{array}{l}70.52 \\
(5.49)\end{array}$ & $\begin{array}{l}\mathrm{AB}=29.6 \% \\
\mathrm{C} 1 \mathrm{C} 2=48.5 \\
\%\end{array}$ & $\begin{array}{l}\text { Male=184 } \\
\mathrm{DE}=21.9 \%\end{array}$ & $\begin{array}{l}\text { Female=181 } \\
(0.92)\end{array}$ & $2.48(1.28)$ & $2.56(1.35)$ \\
\hline
\end{tabular}

Table 5: Average age, socio-economic status. Self-reported health, experience and confidence

\begin{tabular}{|lc|c|c|c|}
\hline \multirow{2}{*}{} & & \multicolumn{2}{|c|}{ conflict with other pedestrians } & \multirow{2}{*}{ Total } \\
\cline { 3 - 4 } & AB & yielded & did not yield & \\
\hline \multirow{3}{*}{ socio economic group } & C1C2 & 6 & 10 & 11 \\
& DE & 8 & 2 & 8 \\
& & & 0 & 8 \\
\multirow{4}{*}{ Gender } & Male & 6 & 7 & 13 \\
& & 9 & 5 & 14 \\
& Female & 15 & 12 & 27 \\
\hline
\end{tabular}

Table 6: Yielding to conflict with other pedestrians by socio-economic group and gender 


\begin{tabular}{|l|l|l|l|}
\hline & \multicolumn{2}{|l|}{ Conflict with other pedestrians } & \\
\hline & Yielded $(\mathrm{n}=15)$ & Did not yield $(\mathrm{n}=12)$ & Sig difference \\
\hline Self-reported health & $2.2(0.94)$ & $1.75(0.62)$ & $\mathrm{t}(24)=1.49 ; \mathrm{p}>0.05$ \\
\hline $\begin{array}{l}\text { Self-reported } \\
\text { experience }\end{array}$ & $2.67(1.29)$ & $2.75(1.06)$ & $\mathrm{t}(25)=0.19 ; \mathrm{p}>0.05$ \\
\hline $\begin{array}{l}\text { Self-reported } \\
\text { confidence }\end{array}$ & $3.07(1.01)$ & $1.75(1.22)$ & $\mathrm{t}(23)=2.92 ; \mathrm{p}<0.01$ \\
\hline
\end{tabular}

Table 7: Yielding to conflict with other pedestrians by self-report measures of health, experience and confidence.

\begin{tabular}{|l|l|l|l|l|}
\hline & $\begin{array}{l}\text { Inside away from } \\
\text { carriageway }\end{array}$ & $\begin{array}{l}\text { Nearest } \\
\text { carriageway }\end{array}$ & Mixed & $\begin{array}{l}\text { In the } \\
\text { carriageway }\end{array}$ \\
\hline Male $(\mathrm{n}=151)$ & $99(53.8 \%)$ & $56(30.4 \%)$ & $19(10.3 \%)$ & $10(5.4 \%)$ \\
\hline Female $(\mathrm{n}=97)$ & $136(75.1 \%)$ & $40(22.1 \%)$ & $4(2.2 \%)$ & $1(0.6 \%)$ \\
\hline $\begin{array}{l}\text { Total } \\
(\mathrm{n}=365)\end{array}$ & $235(64.4 / \%)$ & $96(26.3 \%)$ & $23(6.3 \%)$ & $11(3 \%)$ \\
\hline
\end{tabular}

Table 8: Pedestrian positioning by gender. 


\begin{tabular}{|c|c|c|c|}
\hline & Position & Speed & $\begin{array}{l}\text { Pedestrian-pedestrian } \\
\text { conflict }\end{array}$ \\
\hline Type of road & $\begin{array}{l}\text { Shared space: More } \\
\text { carriageway walking } \\
\text { (especially by males) }\end{array}$ & $\begin{array}{l}\text { Walk quicker in } \\
\text { urban shopping area, } \\
\text { significantly so } \\
\text { compared to shared } \\
\text { space area. }\end{array}$ & Not significant \\
\hline Age & $\begin{array}{l}\text { Younger more likely } \\
\text { to walk nearer } \\
\text { carriageway (but not } \\
\text { significant) }\end{array}$ & Not significant & Not significant \\
\hline Gender & $\begin{array}{l}\text { Males more likely } \\
\text { than females to } \\
\text { inhabit space nearer } \\
\text { carriageway }\end{array}$ & $\begin{array}{lr}\text { Males } & \text { walk } \\
\text { significantly } & \text { faster } \\
\text { than females } & \end{array}$ & $\begin{array}{l}\text { Females more likely } \\
\text { to yield (but non } \\
\text { significant) }\end{array}$ \\
\hline $\begin{array}{l}\text { Socio-economic } \\
\text { status (SES) }\end{array}$ & $\begin{array}{l}\text { Higher SES more } \\
\text { likely to walk nearer } \\
\text { carriageway (but not } \\
\text { significant) }\end{array}$ & $\begin{array}{l}\text { Highest SES group } \\
(\mathrm{AB}) \\
\text { significantly falk } \\
\text { than C1C2 and DE } \\
\text { groups. }\end{array}$ & $\begin{array}{l}\text { Highest SES group } \\
\text { (AB) significantly } \\
\text { less likely to yield }\end{array}$ \\
\hline Health & $\begin{array}{l}\text { Those in better health } \\
\text { compared to poorer } \\
\text { health significantly } \\
\text { more likely to walk } \\
\text { nearer carriageway }\end{array}$ & $\begin{array}{l}\text { Significant positive } \\
\text { correlation between } \\
\text { walking speeds and } \\
\text { health }\end{array}$ & Not significant \\
\hline Experience & Not significant & Not significant & Not significant \\
\hline Confidence & Not significant & $\begin{array}{l}\text { Significant positive } \\
\text { correlation between } \\
\text { walking speeds and } \\
\text { confidence }\end{array}$ & $\begin{array}{l}\text { Significant } \\
\text { difference: those } \\
\text { more confident are } \\
\text { less likely to yield }\end{array}$ \\
\hline
\end{tabular}

Table 9: Summary of relationship between factors 


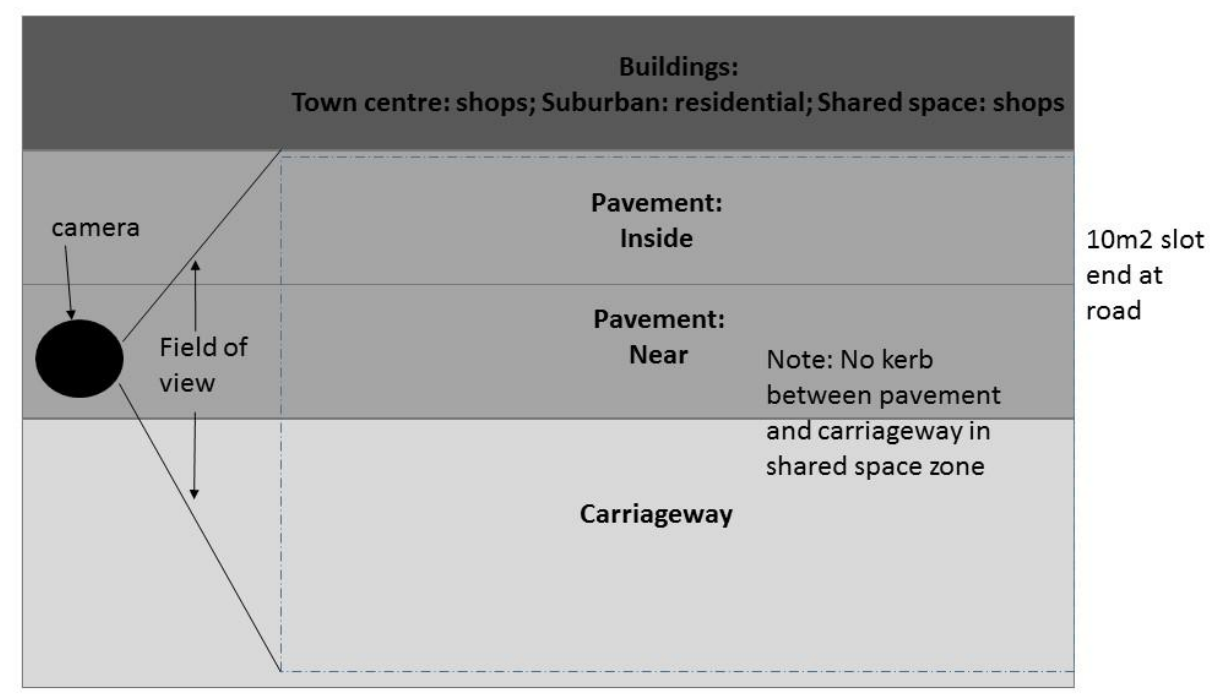

Figure 1: Layout of camera showing field of view for the observations made across all three locations. The pavement was split half way between inside away from the carriageway and near to the carriageway. The carriageway and pavement could still be noted as different in the shared space area despite having no discernable kerb as colouring of the floor is different. Each of the three sections ended in a road joining the carriageway at right angles stopping the continuous pavement. 


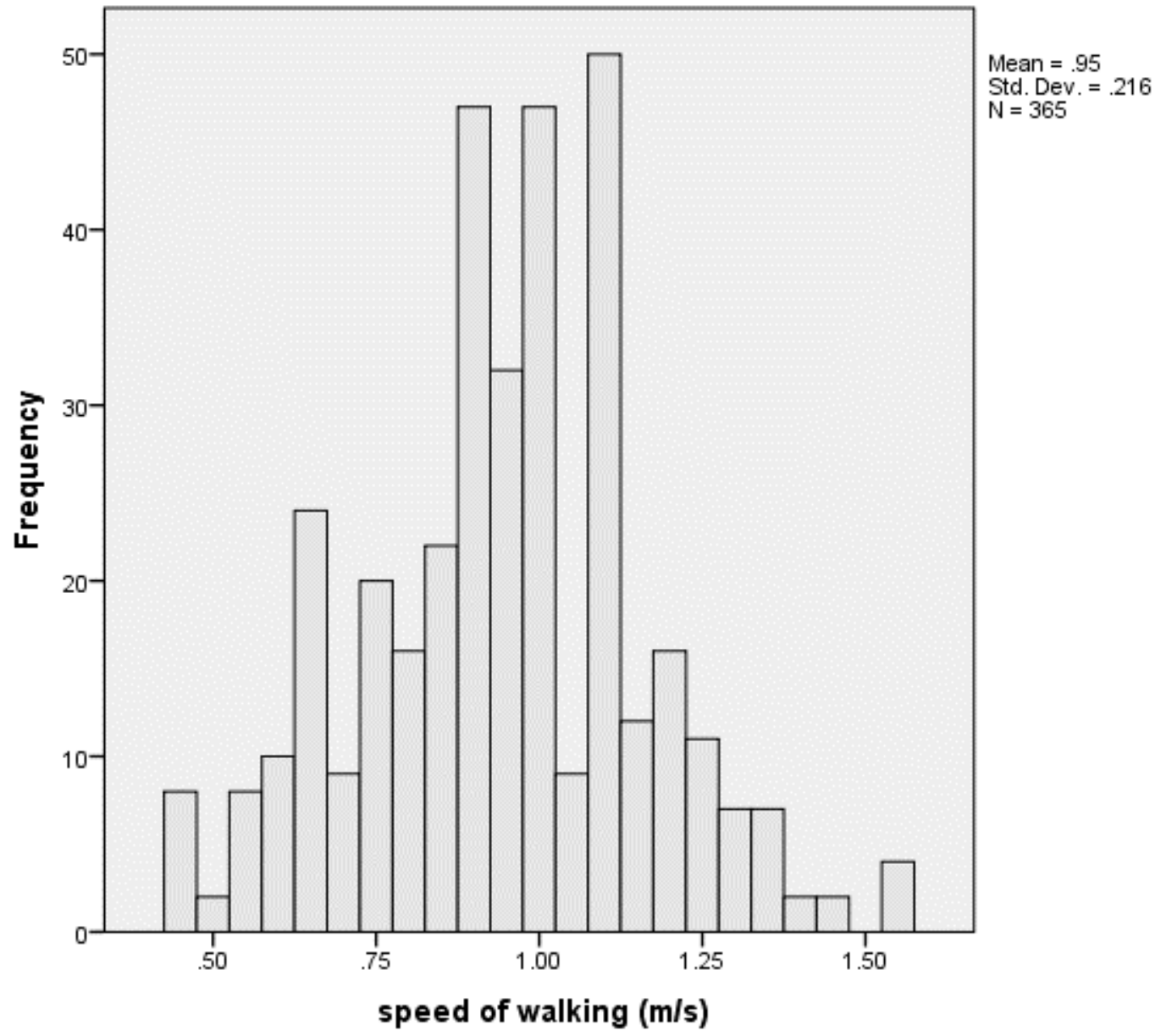

Figure 2: Distribution of walking speeds across all the participants. 